\title{
DISCURSO DE ÓDIO NA INTERNET: A LINHA TÊNUE ENTRE O CRIME E A LIBERDADE DE EXPRESSÃO
}

\section{ARTIGO ORIGINAL}

BARBOSA, Kelianny Pereira ${ }^{1}$, DISCONZI, Verônica Silva Do Prado ${ }^{2}$, TORRES, Leonardo Guimarães ${ }^{3}$

BARBOSA, Kelianny Pereira. DISCONZI, Verônica Silva Do Prado. TORRES, Leonardo Guimarães. Discurso de ódio na internet: a linha tênue entre o crime e a liberdade de expressão. Revista Científica Multidisciplinar Núcleo do Conhecimento. Ano 06, Ed. 06, Vol. 03, pp. 122-136. Junho de 2021. ISSN: 24480959, Link de acesso: https://www.nucleodoconhecimento.com.br/lei/liberdade-deexpressao, DOI: 10.32749/nucleodoconhecimento.com.br/lei/liberdade-de-expressao

\section{RESUMO}

A presente pesquisa analisa as relações entre o avanço do discurso de ódio, principalmente nas redes sociais digitais. Pretende-se compreender até que ponto o exercício da liberdade de expressão torna-se abusivo, incitando a intolerância social através do referido discurso. Ultimamente, diversas pessoas estão utilizando seu direito à liberdade de expressão para agredir o outro. Tais atitudes têm gerado desconforto na sociedade e, atrelado a isso, surge a "cultura do cancelamento", uma onda que incentiva pessoas a deixarem de apoiar determinadas personalidades, em razão de um erro ou de uma conduta reprovável. Essas atitudes geralmente são externadas por um discurso agressivo, fazendo com que a Internet seja um tribunal onde nada passa despercebido e na maioria das vezes as vítimas não têm acesso ao

\footnotetext{
1 Graduação em Direito.

2 Coorientadora. Mestre.

${ }^{3}$ Orientador. Especialista Em Direito Tributário E Em Direito Contratual.
}

$\mathrm{RC}: 87814$

Disponível em: https://www.nucleodoconhecimento.com.br/lei/liberdade-de-expressao 
direito contraditório ou ampla defesa. Para que seja desenvolvida pesquisa jurídica, que propõe o estudo do discurso de ódio na internet, tendo como base os limites da liberdade de expressão e quando essa liberdade é considerada criminosa, utilizar-seá o método hipotético-dedutivo, no qual o estudo se desenvolve a partir de premissas gerais sobre o tema, e ao final chega-se ao estudo específico a respeito do que se deseja discutir. Quanto aos materiais, a pesquisa será desenvolvida com base em pesquisa teórica, com parâmetro descritivo e comparativo, baseado em material bibliográfico e documental legal. Sendo assim, efetuar-se-á breve estudo acerca da problemática envolvendo a liberdade de expressão e o uso inconsequente da internet, sob o parâmetro jurídico, em razão dos bens envolvidos serem tutelados pela Constituição Federal. Constatou-se, pois, que a violência que se manifesta nas redes tem apresentado contornos de preconceito, misoginia, homofobia e totalitarismo, muitas vezes ultrapassando os limites do ciberespaço, um ambiente que tem contribuição na estruturação dos vínculos para a construção da identidade pessoal. É incontestável a importância da liberdade de expressão e sendo algo tão nobre, se faz necessário a imposição de restrições, para evitar o uso leviano desse direito. O Estado deve garantir esse direito fundamental, porém, não de uma maneira ilimitada.

Palavras-chave: Cultura do cancelamento, Discurso de ódio, Liberdade de expressão, Redes sociais.

\section{INTRODUÇÃO}

Entende-se como discurso de ódio os discursos bastante agressivos, proferidos contra minorias justificados pela liberdade de expressão. Com o avanço da internet e das redes sociais essa situação reflete um grande interesse social, devido ao fato de cada dia ser mais comum entre nós. Diante desse contexto, a problemática central da pesquisa é a linha tênue entre o discurso de ódio e a liberdade de expressão. $O$ objetivo geral aqui é analisar esses pretextos mediante as disposições legais presentes atualmente em nosso ordenamento jurídico.

$\mathrm{RC}: 87814$

Disponível em: https://www.nucleodoconhecimento.com.br/lei/liberdade-de-expressao 
A pesquisa irá contribuir para elevar o nível de conhecimento no campo estudado por se tratar de um tema contemporâneo, com baixo número de instruções sobre o assunto, porém, de amplo interesse social, que a partir daqui poderá estimular a realização de novas pesquisas.

\section{CONCEPTUALIZAÇÃO DO DISCURSO DE ÓDIO}

A princípio, usaremos as palavras de Michel Foucaut para conceitualizar o termo "discurso". Ele ressalta que: "Chamaremos de discurso um conjunto de enunciados, na medida em que se apoiem na mesma formação discursiva; ele é constituído de um número limitado de enunciados, para os quais podemos definir um conjunto de condições de existência (...)" (FOUCAULT, 1997, p. 135-136).

Sabemos que o discurso é algo extremamente importante e inerente ao ser humano. Indispensável ao exercício da evolução social, principalmente em uma sociedade democrática de direito, sendo a principal ferramenta para exercer o direito à liberdade de expressão.

Entretanto, atualmente é possível observar uma onda de discursos bastante agressivos, proferidos contra minorias, sob vários instrumentos de comunicação, em especial, nas redes sociais. Todas as pessoas que expõem visões agudamente preconceituosas e criam um ambiente violento se baseiam no seu direito à liberdade de expressão e, a partir daí constroem um ambiente com a propagação de ideias excludentes (CUNHA, 2019).

A liberdade de expressão foi uma pauta consolidada nos movimentos liberais burgueses, em um ângulo financeiro/econômico. Por meio desta liberdade de expressão que os Estados mais modernos foram constituídos, formando diversas sociedades. Nessas sociedades o ser humano tem sua dignidade respeitada, a primeiro modo, nos textos legais (CUNHA, 2019).

$\mathrm{RC}: 87814$

Disponível em: https://www.nucleodoconhecimento.com.br/lei/liberdade-de-expressao 
Essa concepção foi desenvolvida com o Estado Liberal, na medida em que demandas sociais foram surgindo e desigualdades materiais foram crescendo, consequentemente, um novo tratamento ao conceito de liberdade foi assimilado às estruturas estatais e os direitos sociais ganharam notoriedade (CUNHA, 2019).

A democracia construída nos Estados, caracterizada por padrões liberais, contemplou a liberdade de expressão e considerou inclusive o discurso de ódio, pois a liberdade prevaleceu sobre a dignidade do ofendido. Ademais, (FREITAS e CASTRO, 2013, p. 345) imperou a aceitação dos referidos discursos, visto que, pela ótica liberal mercadológica, o melhor discurso sobressaía aos demais.

De acordo com Waldron, (2012), a utilização do termo "discurso de ódio" deve ser substituída pela denominação "difamação coletiva", pois trata-se, em sua concepção, da ação de difamar grupos inteiros. Isso transmite uma mensagem negativa não só para esses grupos, como também para toda a sociedade, criando-se um clima de insegurança e hostilidade contra os seus membros. O termo importa num significado mais abrangente do que o da simples ofensa à honra de um indivíduo ou de um grupo, uma vez que traria consequências diretas à sociedade.

Há uma extensa lista de exemplos históricos de sociedades que, tomadas por esse tipo de discurso, levaram ao pé da letra a desumanização de populações inteiras, ao ponto do seu extermínio em massa. Talvez o exemplo mais notório nos nossos tempos seja o Holocausto, que teve palco na Alemanha nazista, durante a Segunda Guerra Mundial.

As consequências do discurso de ódio não são mero acaso, sendo próprio dessa expressão a incitação, justificação, difusão e/ou promoção da intolerância, conforme consta descrito em documentos oficiais e literatura a respeito do tema. Podemos considerar, então, que muito embora haja uma série de efeitos potenciais ou diretos que derivam desse fenômeno, haverá num primeiro plano a agressão à dignidade da pessoa humana.

$\mathrm{RC}: 87814$

Disponível em: https://www.nucleodoconhecimento.com.br/lei/liberdade-de-expressao 
Para Barroso (2012), é possível e necessário que se crie uma definição transnacional que unifique e universalize a identidade do conceito de dignidade humana, dada sua generalidade nos ordenamentos jurídicos quando a adotam como imperativo. Nessa proposta, elabora-se um conceito que reside em três premissas: o valor intrínseco do ser humano, a sua autonomia e o valor da comunidade.

Enquanto o valor intrínseco seria aquele inerente aos seres humanos, independentemente de qualquer outro fator, e a autonomia seria a possibilidade de os indivíduos se desenvolverem de acordo com as suas próprias convicções, a dignidade humana seria uma espécie de dimensão social do conceito, que projeta sobre a autonomia individual uma limitação, por ordem dos valores da comunidade e pelas normas do Estado (CARPINELLI, 2017).

Utilizando a conceptualização proposta por Barroso, podemos identificar que o discurso de ódio tem como escopo diminuir o valor intrínseco de determinados indivíduos, sob a justificação de serem estes menos dignos. As justificações contidas nessas narrativas são claramente identificadas com motivação religiosa, racial, étnica, sobre nacionalidade ou orientação sexual (CARPINELLI, 2017).

Dessa forma, e ao aderir-se ativamente a uma narrativa que justifique, promova, incite ou difunda a ideia de que alguns seres humanos são menos dignos do que outros é destruída a fundamentação que permite a conclusão de que são titulares de direitos fundamentais, tal qual os seus iguais (CARPINELLI, 2017)

A primeira consequência que surge é a justificação para a discriminação, que tende a advir desse tipo de concessão a respeito do outro. Essa conclusão deriva da relação de proximidade que guardam o princípio da igualdade e o princípio da dignidade da pessoa humana, na medida em que conferir igual tratamento seria o mesmo que conferir igual dignidade a todas as pessoas (CARPINELLI, 2017)

Carpinelli (2017) defende que as pessoas serão tratadas de modo diferente pelo direito em qualquer sociedade, mas, mesmo assim, admitir que as pessoas sejam

RC: 87814

Disponível em: https://www.nucleodoconhecimento.com.br/lei/liberdade-de-expressao 
tratadas de modo diferente quando iguais seria o mesmo que negar a afirmação de que todos os seres humanos são possuidores de igual dignidade.

\subsection{O DISCURSO DE ÓDIO NA INTERNET}

O discurso de ódio também é conhecido pelo termo hate speech, em inglês. É ainda um desafio para o Estado de Direito, por estar nos limites da liberdade de expressão. Com a internet e as mídias sociais, principalmente as redes sociais, ficou ainda mais fácil disseminar esse tipo de discurso. As redes sociais nos proporcionam uma visibilidade jamais alcançada antes, e há quem diga que, uma vez publicado nestas redes, aquele arquivo ou mídia nunca mais sairá de lá.

A possibilidade de anonimato oferecida por essas plataformas é um grande atrativo para quem quer propagar esse tipo de discurso na maioria das vezes. Há uma sensação de poder e de impunidade que, em conjunto com a ignorância e o preconceito impulsiona o Hater a publicar sua ira, em velocidade digital.

A liberdade de expressão, de uma maneira generalizada, é um ato inconsequente e instantâneo, ligado a personalidade do indivíduo, que demonstra sua forma de pensar e opinar determinados assuntos conforme seus princípios.

Se questiona a similaridade do discurso de ódio com a liberdade de expressão nas redes sociais. Devido ao fato de as redes sociais serem plataformas com perfis diversificados, onde cada usuário possui a sua particularidade e a dessemelhança entre eles é gigantesca, é comum que na grande maioria das vezes as pessoas não compartilhem dos mesmo gostos e ideais, o que acaba gerando transtornos e situações conflitantes.

Com o avanço da comunicação tecnológica, veio a chamada "era digital", onde as manifestações se tornaram cada vez mais comuns e corriqueiras, principalmente de uma maneira mais informal. Partindo da concepção de que na internet não existe nenhum modo de contato físico, os usuários se sentem mais protegidos e encorajados

RC: 87814

Disponível em: https://www.nucleodoconhecimento.com.br/lei/liberdade-de-expressao 
a exporem suas opiniões sem impor limites. Isso leva a ideia de que não existem regras no ambiente virtual, e que os ditames do direito não chegam até lá (SIPELLI, 2020).

Salienta-se que, o discurso de ódio atualmente é um dos meios mais lesivos no mundo digital. Esse tipo de discurso enfatiza a manifestação de pensamento inadequada, com o foco na intolerância, resultando em diversas praticas do ato ilícito e do abuso de direito. Na grande maioria dos casos, os usuários contribuem com a propagação de comentários ou publicações de cunho racista, preconceituoso e até mesmo com incitação à violência (SIPELLI, 2020).

Correlacionado ao discurso de ódio, a cultura do cancelamento, que é uma nova modalidade de boicote, vem ganhando força nas redes sociais. Os danos são alarmantes devido as narrativas decadentes. É extrapolado o conceito de liberdade de expressão e das normativas legais (SIPELLI, 2020).

\subsection{A CULTURA DO CANCELAMENTO}

De acordo com o dicionário australiano Macquarie, a "cultura do cancelamento" foi eleita o termo do ano de 2019 e mesmo não tendo um marco exato de origem, teve início aparentemente desde a mobilização de vítimas de assédio e abuso sexual, no movimento \#MeToo, com maior visibilidade em 2017, pela força das denúncias realizadas em Hollywood.

A cultura do cancelamento basicamente é uma onda que incentiva pessoas a deixarem de apoiar determinadas personalidades ou empresas, em razão de um erro ou de uma conduta reprovável. A ideia do movimento é literalmente "eliminar" ou "tornar sem efeito" o agente do erro ou conduta, tidos como reprováveis. Essa cultura tem chamado bastante atenção, principalmente nas redes sociais, por tratar-se de uma onda muito forte e recorrente, que incentiva pessoas a excluírem determinadas personalidades (SILVA; HONDA, 2021).

$\mathrm{RC}: 87814$

Disponível em: https://www.nucleodoconhecimento.com.br/lei/liberdade-de-expressao 
É uma cultura preocupante, pois ao contrário do Direito em que há um devido processo legal para justificar uma punição ou não, o famoso "tribunal da internet" não costuma sequer oferecer o exercício do contraditório. Na maioria das vezes os efeitos são imediatos, e os boicotes acontecem em questão de minutos, expondo todos os erros da pessoa ou empresa, criando um movimento na rede social de exposição, fazendo que seus usuários deixem de seguir aquela pessoa e/ou empresa, fazendo também com que o público deixe de comprar determinada marca, por ser representada por tal pessoa.

As pessoas que ficam diante de tantos julgamentos e sanções imediatamente impostas sem a possibilidade de defesa optam por não compartilhar seus pensamentos sobre determinados temas por receio do cancelamento e dos danos psicológicos, de imagem e patrimoniais dele decorrentes. O que nos leva ao pensamento de que não dá para mensurar os danos que essa cultura traz, principalmente por sermos seres humanos em constante evolução.

O que não se pode esquecer é da forte ligação entre a cultura do cancelamento, a publicidade e o marketing digital, que cresce cada dia mais e associam as relações de consumo através da imagem de pessoas públicas, ou seja. Conhecidas pela sociedade. Há então uma definição de estereótipos, que se torna inevitável.

Isso faz com que o público adquira aqueles produtos e serviços oferecidos por essas pessoas, e fiquem sedentos pela rotina dessas pessoas e todos os seus atos. $O$ resultado, infelizmente é a pressão para não errar, pois, qualquer deslize ou conduta considerada reprovável, acarreta um boicote coletivo que é a maneira de punir da população em massa.

\section{OS DIREITOS FUNDAMENTAIS E A LIBERDADE DE EXPRESSÃO}

O instrumento jurídico mais utilizado nos debates sobre o discurso do ódio é o Pacto Internacional sobre Direitos Civis e Políticos, embora não contenha explicitamente no pacto esse termo. Seu artigo 19 prevê a garantia do direito à liberdade de expressão

RC: 87814

Disponível em: https://www.nucleodoconhecimento.com.br/lei/liberdade-de-expressao 
explicitando, contudo, que tal direito enseja também deveres. $\mathrm{O}$ artigo prevê que a liberdade de expressão poderá estar sujeita a restrições que devem ser previstas em lei.

O artigo 20 estabelece proibição formal a "qualquer apologia do ódio nacional, racial ou religioso que constitua incitamento à discriminação, à hostilidade ou a violência" (REPÚBLICA, 1989). A inclusão desta disposição incorpora ao Pacto uma concepção particular do discurso do ódio que, no entanto, tem sido profundamente contestada.

De um lado, houveram diversos questionamentos acerca de uma possível contradição entre a garantia ao direito à liberdade de expressão e as restrições impostas no artigo 20 que permitem uma gama de interpretações muito ampla, abrindo campo para a ação de estados autoritários.

Por outro lado, organizações da sociedade civil levantaram preocupação pelo fato da indefinição acerca do que é discurso de ódio abrir espaço para grupos específicos praticarem toda sorte de discurso discriminatório (GAGLIARDONE et al., 2015).

O debate em torno da abordagem do Pacto Internacional sobre Direitos Civis e Políticos corrobora a ideia de que, buscar uma definição do que é discurso de ódio talvez não seja uma abordagem adequada pela perspectiva da construção de políticas públicas ou mesmo do ambiente legal e regulatório. Como consequência, a formação do sistema normativo regional também avança buscando tratar demandas culturais específicas. Alguns dos exemplos são a Convenção Americana Sobre Direitos Humanos de 1969 (OEA, 1969) e a Carta Africana dos Direitos Humanos e dos Povos de 1979 (CADHP, 1979).

No Brasil, somente após o processo de redemocratização que o estado brasileiro começa a ratificar tratados internacionais de direitos humanos. A Constituição Federal de 1988, também chamada de Constituição Cidadã, introduz importante inovação ao estabelecer a prevalência dos direitos humanos como princípio orientador das 
relações internacionais, atribuindo coerência ao texto da lei em relação às transformações sociais e políticas vividas pelo país nos anos finais da ditadura militar.

Nossa atual Constituição é um marco jurídico da institucionalização dos direitos humanos no Brasil, simbolizando a ruptura com o regime autoritário imposto pelo Exército Brasileiro.

A liberdade de expressão é prevista na Constituição Federal como direito fundamental em seu artigo 50, inciso IV constituindo-se sua tutela na consagração da plena autonomia para o seu exercício (BRASIL, 1988). Entretanto, ela está referida no sistema constitucional pelo princípio da legalidade, o que condiciona a fruição desse direito à integralidade do ordenamento jurídico, seja através de normas constitucionais, submetendo-a a valores expressos na constituição como a dignidade humana, seja através de normas infraconstitucionais que tipificam condutas ilícitas, como é o caso da lei 7.716/899, que veda a prática de discriminação em razão de cor, raça, etnia, procedência nacional ou religião (FREITAS; CASTRO, 2013).

Mill (1869) defende que a verdade só pode triunfar como resultado de um debate aberto e livre de ideias e parte do princípio que os homens são passíveis de falha ao tentar identificar a verdade na manifestação e defesa de suas convicções. Só o confronto de ideias pode levar a construção da verdade e qualquer tentativa de supressão de uma ideia presume a infalibilidade das ideias dos homens. Segundo o autor, o cerceamento da liberdade de expressão ocorre em prejuízo de todos, inclusive de futuras gerações, pois é como se a disparidade das ideias que predominam em diferentes momentos históricos fosse negada (MILL, 1869).

Em 1966 a Convenção Internacional sobre a Eliminação de todas as Formas de Discriminação Racial amplia a defesa contra o discurso de ódio ao declarar em seu artigo IV que toda a disseminação de ideias baseadas em superioridade racial, ódio, discriminação racial, atos de violência ou incitação a atos de violência, ou provisionamento para assistir de qualquer forma tais atos contra pessoas em razão de sua cor, raça ou origem, deve ser punida por lei (UNESCO, 1966).

RC: 87814

Disponível em: https://www.nucleodoconhecimento.com.br/lei/liberdade-de-expressao 
O Pacto Internacional sobre Direitos Civis e Políticos, em seu artigo 20 estabelece que deverá ser proibido por lei "qualquer apologia do ódio nacional, racial ou religioso que constitua incitamento à discriminação, à hostilidade ou a violência". Alemanha, França e Países Baixos incorporaram os princípios oriundos de tratados internacionais em seus ambientes legais como forma de proteção às externalidades geradas pelo discurso de ódio. Determinados tipos de manifestação foram sumariamente proibidos nesses países, o que, diferentemente da abordagem americana, estabelece limites claros à liberdade de expressão (TSESIS, 2009).

\section{O CONFLITO ENTRE A LIBERDADE DE EXPRESSÃO E O DISCURSO DE ÓDIO NO ORDENAMENTO JURÍDICO BRASILEIRO}

Há uma interpretação de que a Constituição Federal prevê restrições ao discurso de ódio quando os artigos $5^{\circ}$, incisos XLI e XLII estipulam que "a lei punirá qualquer discriminação que viole direitos e liberdades fundamentais" e "de acordo com a lei, o comportamento racista constitui um crime indescritível e deve ser punido com a prisão" (BRASIL, 1984).

$\mathrm{O}$ art. 3ํㅡㄹ inciso IV, da Carta Magna estipula a obrigação de promover os interesses de todas as pessoas, sem prejuízo de origem, raça, sexo, cor, idade e quaisquer outras formas de discriminação (BRASIL, 1984).

De acordo com Sarmento 2007 diante a desigualdade social, o Estado deve realizar ações positivas para garantir que o debate público seja real e legalmente conduzido.

Apesar de não ter legislação específica no Brasil sobre o Discurso de Ódio, alguns casos chegam ao judiciário e tiveram algumas soluções. Podemos citar um grande caso que apresenta características evidentes de intolerância e hostilidade tornandose objeto de exclusão pública e social.

Um exemplo clássico é o caso do editor Siegfried Ellwanger, que ao escrever e publicas livros, condenou publicamente o racismo e o antissetismo, mas espalhou ódio

RC: 87814

Disponível em: https://www.nucleodoconhecimento.com.br/lei/liberdade-de-expressao 
aos judeus. Ele se referiu aos judeus como uma sub-raça, causadora de todas as tragédias do Holocausto. Nesse caso, o Ministro Marco Aurélio descreveu tal julgamento como um dos mais importantes do STF. Em seu voto, o Ministro Celso de Mello evidencia que a narrativa supera a questão de se cometer crimes raciais, pois simboliza crimes insuportáveis contra a humanidade. Em apoio ao ministro Marco Aurélio. Ele alegou: "As pessoas que ofendem a dignidade de qualquer pessoa, especialmente aquelas que são movidas devido à natureza do racismo, ofendem a dignidade de todos" (BRASIL, 2020).

É evidente o conflito entre a liberdade de expressão e outros direitos básicos, confirmando que não existe hierarquia entre garantias previstas no texto constitucional, mas sim interpretação adequada das mesmas para que os conflitos de interesses sejam resolvidos de forma proporcional e harmoniosa.

A liberdade de expressão é princípio e direito fundamental no nosso ordenamento jurídico. Consequente, em determinadas situações haverá um choque entre direitos fundamentais, que apesar de não ser uma decisão fácil sobre qual direito sobressairá frente ao outro, é extremamente normal. Isso significa que nenhum direito fundamental é absoluto, inclusive a liberdade de expressão. Por isso é importante resguardar esses direitos, todos eles, e não somente a liberdade de expressão.

Importante destacar que resguardar não significa censurar. Isso não passa de uma conclusão equivocada, tendo em vista que a censura pressupõe uma exceção prévia a manifestação do pensamento ou, ainda, um silenciamento com base em pressupostos ideológicos-políticos, o que se diferencia responsabilização de pessoas que vão além da liberdade de expressão ao ponto de lesarem outros direitos, ou até mesmo, cometerem crimes.

Custódio (2019) afirma que: "uma coisa é a censura, totalmente inadmissível, outra coisa é a responsabilização de pessoas que extrapolam os limites e lesam o direito de outras pessoas". Constata-se pelos posicionamentos do Supremo Tribunal Federal a respeito da matéria:

RC: 87814

Disponível em: https://www.nucleodoconhecimento.com.br/lei/liberdade-de-expressao 
Nesse contexto e de acordo com a precisa e oportuna síntese de Daniel Sarmento, muito embora a posição adotada pelo Ministro Carlos Ayres de Britto no julgamento da ADPF n. 130, quando sustentou que nenhum limite legal poderia ser instituído em relação à liberdade de expressão, pois as limitações existentes seriam apenas aquelas já contempladas no texto constitucional, cabendo tãosomente ao Poder Judiciário fazer as ponderações pertinentes em caso de tensões com outros direitos, o Ministro Gilmar Ferreira Mendes, no voto condutor que proferiu no Recurso Extraordinário n. $511.961 / \mathrm{SP}$, observou que as restrições à liberdade de expressão em sede legal são admissíveis, desde que visem a promover outros valores e interesses constitucionais também relevantes e respeitem o princípio da proporcionalidade (BRASIL, 2009).

Nota-se então que a nossa Carta Magna estabelece limites a liberdade de expressão, pois esses limites se fundam em outros direitos constitucionais resguardados, que são objeto de tutela do direito penal por meio dos crimes contra a honra.

Custódio (2019) entende que quando há responsabilização de pessoas pelos excessos na liberdade de expressão, não se trata, de forma alguma, de censura. Trata-se do resguardo de direitos fundamentais tão relevantes quanto a liberdade de expressão e que devem ser respeitados.

Não se condena alguém por suas opiniões, ideologias, princípios e visões de mundo. Condena-se pelo abuso e excesso da liberdade de expressão quando fere outros direitos fundamentais de pessoas que merecem a mesma proteção. Afinal, a lei garante o tratamento igualitário entre todos os indivíduos. Trata-se de uma medida de ponderação do próprio direito, onde nenhuma regra ou princípio são absolutos.

\section{CONSIDERAÇÕES FINAIS}

A democracia representa em sua essência a participação de todos, principalmente na formação da vontade estatal e a liberdade de expressão se apresenta como uma forma de se participar ativamente de assuntos do interesse público, porém as manifestações de cunho odioso se apresentam como uma forma de diminuir a diversidade nos espaços públicos por causar um temor e impedir, até pela violência 
verbal com que é conduzida essa manifestação, participação das minorias na vontade estatal.

A liberdade de expressão é fundamentada na igualdade, sendo um dos grandes pilares do modelo democrático. É a exteriorização das crenças e dos pensamentos do homem frente a sociedade. Mas, mesmo sendo de suma importância, não deve ser entendida como um direito absoluto.

A maior corrente doutrinária entende que apesar de ser um direito fundamental, não pode ser entendido como um direito absoluto e deve ser cerceado a partir do momento que ferir outrem. Dentre as várias formas abusivas do uso da liberdade de expressão, o presente estudo abordou a questão do discurso de ódio, focando na sua conceituação e formas de incidências, bem como consequências.

Sendo assim, conclui-se que o discurso de ódio, é a forma de comunicação que busca promover o ódio, justificando-se no direito à liberdade de expressão e na livre manifestação, como forma de discriminar, inferiorizar e incitar a violência. A maioria dos alvos desse discurso tão violento são características como, raça, gênero, nacionalidade, orientação sexual, e etnia diferentes.

Percebe-se então, que os limites entre o discurso de ódio e a liberdade de expressão ainda são de difícil delimitação em uma linha tênue, transferindo para o judiciário esses problemas, em busca de suas resoluções.

O debate a respeito do limite das liberdades é essencial, devendo haver o enfrentamento real dessas questões, buscando minimizar ondas de violência que já são tão presentes em nosso cotidiano.

Por fim, comprova-se que é incontestável a importância da liberdade de expressão e por ser algo tão nobre, se faz necessário impor restrições, para evitar o uso leviano desse direito. O Estado deve garantir esse direito fundamental, porém, não de uma maneira ilimitada.

RC: 87814

Disponível em: https://www.nucleodoconhecimento.com.br/lei/liberdade-de-expressao 


\section{REFERÊNCIAS}

BRASIL. Constituição (1988). Constituição da República Federativa do Brasil. Brasília, DF: senado, 1988.

BRASIL. Supremo Tribunal Federal. Ementa no 2381-1. Relator: MIN. CARLOS BRITTO. Brasília, DF, 05 de novembro de 2009. Arguição de Descumprimento de Preceito Fundamental 130 Distrito Federal. Brasília, 06 nov. 2009. p. 1-334. Disponível

em: http://redir.stf.jus.br/paginadorpub/paginador.jsp?docTP=AC\&doclD=605411. Acesso em: 23 mar. 2021.

BARROSO, Luís Roberto. Here, There, and Everywhere: Human Dignity in Contemporary Law and in the Transnational Discourse, 35 B.C. Int'l \& Comp. L. Rev. 331 (2012), pp. 331-393

CADHP. Carta Africana dos Direitos Humanos e dos Povos. 1979. Disponível em: <http://www.achpr.org/pt/instruments/achpr/>. Acesso em: 23 Mar. 2021.

CARPINELLI, André Turella. Discurso De Ódio E Liberdade De Expressão: Permissão, Proibição E Criminalização No Atual Cenário Sociopolítico Ocidental. 2017. 114 f. Dissertação (Mestrado) - Curso de Mestrado em Direitos Fundamentais, Universidade de Lisboa, Lisboa, 2017. Disponível em: https://repositorio.ul.pt/bitstream/10451/37573/1/ulfd137531_tese.pdf. Acesso em: 01 mar. 2021.

CUNHA, Felipe Goulart. A tensão entre o direito à liberdade de expressão e o discurso de ódio no panorama judicial e democrático brasileiro. 2019. 63 F. TCC (Graduação) - Curso De Direito.

CUSTÓDIO, Roberto Montanari. Os Limites da Liberdade de Expressão: uma coisa é censura, outra é responsabilização. 2019. Disponível em: 
http://www.justificando.com/2019/05/03/os-limites-da-liberdade-de-expressaocensura-e-responsabilizacao/. Acesso em: 23 mar. 2021.

FREITAS, Riva Sobrado de; CASTRO, Matheus Felipe de. Liberdade de expressão e discurso do ódio: um exame sobre as possíveis limitações à liberdade de expressão. Sequência, Florianópolis, v. 34, n. 66, p. 327-355, julho. 2013.

Universidade Federal De Uberlândia, Uberlândia, 2019. Disponível Em: Https://Repositorio.Ufu.Br/Bitstream/123456789/28238/4/Tens\%C3\%a3oentredireito. Pdf. Acesso em: 01 Mar. 2021.

FREITAS, R. S. D.; CASTRO, M. F. D. Liberdade de Expressão e Discurso do Ódio: um exame sobre as possíveis limitações à liberdade de expressão. Seqüência: Estudos Jurídicos e Políticos, v. 34, n. 66, jul. 2013. ISSN 2177-7055, 0101-9562. Disponível em: <https://periodicos.ufsc.br/index.php/sequencia/article/view/28064>. Acesso em: 23 Mar. 2021.

FOUCAULT, M. A arqueologia do saber. Rio de Janeiro: Forense Universitária, 1997.

GAGLIARDONE, I. et al. Countering online hate speech. Paris: UNESCO, 2015. ISBN 978-92-3-100105-5.

MILL, J. S. On liberty. [S.I.]: Longmans, Green, Reader, and Dyer, 1869.

OEA. Convenção Americana sobre Direitos Humanos. 1969. Disponível em: $<$ https://www.cidh.oas.org/basicos/portugues/c.convencao_americana.htm>. Acesso em: 23 Mar. 2021.

REPÚBLICA, P. Decreto Presidencial. Atos Internacionais. Pacto Internacional sobre Direitos Civis e Políticos. 1992. Disponível em: <http://www.planalto.gov.br/ccivil_03/decreto/1990-1994/d0592.htm>. Acesso em: 23 Mar. 2021.

$\mathrm{RC}: 87814$

Disponível em: https://www.nucleodoconhecimento.com.br/lei/liberdade-de-expressao 
REPÚBLICA, P. da. Lei número 7716/1989. Define os crimes resultantes de preconceito de raça ou de cor. 1989. Disponível em: <http://www.planalto.gov.br/ccivil_03/leis/_L7716.htm>. Acesso em: 23 Mar. 2021.

SILVA, Thays Bertoncini da; HONDA, Erica Marie Viterito. O "Tribunal da Internet" e os efeitos da cultura do cancelamento. Disponível em: https://www.migalhas.com.br/depeso/331363/o--tribunal-da-internet--e-os-efeitos-dacultura-do-cancelamento. Acesso em: 22 mar. 2021.

SIPELLI, Wallace. O discurso de ódio nas redes sociais e os efeitos causados pela cultura do cancelamento. Revista Jus Navigandi, ISSN 1518-4862, Teresina, ano 25, n. 6271, 1 set. 2020. Disponível em: https://jus.com.br/artigos/85074. Acesso em: 20 mar. 2021.

TSESIS, A. Dignity and Speech: The Regulation of Hate Speech in a Democracy. Rochester, NY, 2009. Disponível em: <http://papers.ssrn.com/abstract=1402908>. Acesso em: 23 Mar. 2021.

UNESCO. Convenção da ONU sobre a Eliminação de todas as Formas de Discriminação $\quad$ Racial. $1966 . \quad$ Disponível $\quad$ em: <http://unesdoc.unesco.org/images/0013/001393/139390por. pdf>. Acesso em: 23 Mar. 2021.

WALDRON, J., The Harm in Hate Speech, Harvard, 2012, versão e-book, Kodo.

Enviado: Maio, 2021.

Aprovado: Junho, 2021.

RC: 87814

Disponível em: https://www.nucleodoconhecimento.com.br/lei/liberdade-de-expressao 